\title{
A Chronic Care Ostomy Self-Management Program for Cancer Survivors
}

\author{
Robert S. Krouse, $\mathrm{MD}^{1,2}$ \\ Marcia Grant, RN, PhD, FAAN ${ }^{3}$ \\ Ruth McCorkle, RN, PhD, FAAN ${ }^{4}$ \\ Christopher S. Wendel, MS ${ }^{1,2}$ \\ Martha D. Cobb, MS, MEd, $\mathrm{CWOCN}^{5}$ \\ Nancy J. Tallman, BSN, WOC Nurse ${ }^{6}$ \\ Elizabeth Ercolano, RN, MSN, DNSc${ }^{4}$ \\ Virginia Sun, $\mathrm{RN}, \mathrm{PhD}^{3}$ \\ Judith H. Hibbard, DrPH, MPH ${ }^{7}$ \\ Mark C. Hornbrook, $\mathrm{PhD}^{8}$
}

\author{
Author Affiliations \\ ${ }^{1}$ Southern Arizona Veterans Affairs Health Care System, Tucson, AZ \\ ${ }^{2}$ University of Arizona College of Medicine, Tucson, AZ \\ ${ }^{3}$ City of Hope National Medical Center/Beckman Research Institute, Duarte, CA \\ ${ }^{4}$ Yale School of Nursing, New Haven, CT \\ ${ }^{5}$ University of Arizona College of Nursing, Tucson, AZ \\ ${ }^{6}$ Wound Ostomy Continence Nurse, Unaffiliated, Tucson, AZ \\ ${ }^{7}$ University of Oregon, Eugene, OR \\ ${ }^{8}$ Kaiser Permanente Center for Health Research, Portland, OR \\ Address Correspondence and Reprint Requests to: \\ Robert S. Krouse, MD \\ Professor of Surgery \\ Southern Arizona VA Health Care System \\ Surgical Care line, 2-112 \\ 3601 S. 6th Ave \\ Tucson, AZ 85723 \\ (520) $792-1450$ ext. 16145 \\ robert.krouse@va.gov
}

Running Head: Chronic Care Ostomy Self-Management Program

Key Words: Cancer, Oncology, Ostomy, Self Care, Chronic Care Model, Cancer Survivorship Word Counts:

Abstract $=246$ [250 word limit]

Text $=3,209$ [4000 word limit]

Tables $=4$

Figures $=0$

Number of References $=40$ 


\section{ABSTRACT \\ Background}

Individuals with ostomies experience extensive changes in health-related quality of life (HRQOL) and daily routine. Patients and families are typically forced to use trial-and-error to improve self-management.

\section{Methods}

This is a longitudinal one-group design pilot study of a five-session ostomy self-care curriculum based on the Chronic Care Model to improve HRQOL and self-management for cancer survivors with ostomies. Participants were surveyed to evaluate each session. Multiple instruments were administered to examine outcomes at baseline, post-intervention, and at six-month follow-up (Patient Activation Measure, Self-Efficacy, Hospital Anxiety and Depression Scale, Ways of Coping, Group Health Association of America Satisfaction with Ostomy Care Survey, and the City of Hope Quality of Life - Ostomy). Changes from pre- to post-intervention and preintervention to follow-up were evaluated with paired t-tests. Text responses were coded and evaluated for important themes and recommendations.

\section{Results}

Thirty-eight subjects participated in the study. Most had a history of rectal cancer $(60.5 \%)$ or bladder cancer (28.9\%). Participants rated the overall program high (4.4-4.8 on 5-point scale). Text feedback indicated that participants enjoyed the group forums, wanted more participants, and more hands-on training. Scores on multiple surveys were shown to be improved and sustained, including Patient Activation $(\mathrm{p}=0.0004)$, Self-Efficacy $(\mathrm{p}=0.006)$, Total HRQOL $(p=0.01)$, physical well-being $(p=0.005)$, and social well-being $(p=0.002)$. Survivor anxiety was significantly reduced by follow-up $(\mathrm{p}=0.047)$.

\section{Conclusions}

This self-management ostomy program can help cancer survivors with ostomies adapt to their stoma. Initiating this program in the community setting would be beneficial to many cancer survivors. 


\section{INTRODUCTION}

An ostomy (or intestinal stoma) is a surgically created opening on the anterior abdominal wall that allows for individuals with various medical conditions to eliminate wastes. Many patients will need an ostomy as part of their cancer treatments, most commonly from cancers of the rectum and bladder. While some ostomies may be intended to be temporary, circumstances require many patients to have an ostomy for months if not permanently. The changes in an individual's quality of life and daily routine are often extensive [1,2]. This impact includes physical, psychological, social, and spiritual issues $[3,4]$.

No standard of usual care exists for supporting adjustment to an ostomy after cancer patients have undergone their stoma surgeries. While formal teaching may begin preoperatively and continue postoperatively, it often does not [5]. As hospital stays have shortened, so has the time available for ostomy teaching and practice. Therefore, patients and families are often left to trial-and-error methods to improve self-management [6]. Typically, only when there are severe problems noted will surgeons and/or ostomy nurses be involved. In the hospital setting, other forms of information, such as booklets and websites, may be biased from ostomy product companies, anecdotal without rigorous analysis, or variable in content [7].

Our team has developed a novel curriculum to assist cancer survivors to understand and adjust to ostomies [8]. This was designed to improve the multiple domains of health-related quality of life (HRQOL) utilizing the Chronic Care Model through planned, proven strategies, management, and patient activation [9]. The chronic care model was developed as an organizing framework for improving care at both the individual and population level. Self-management is an essential component of the model in which partnerships are formed between patients and providers. These partnerships help to empower patients so they can ultimately manage their own care. The program was developed based on extensive research of survivors with ostomies [1$4,6,10-15]$, and designed to be participative with peer support from other cancer survivors with an ostomy. This is a report of feasibility testing of this program along with examining effectiveness and participant satisfaction.

\section{METHODS}

This is a longitudinal one-group design pilot trial of a five-session ostomy selfmanagement curriculum based on the Chronic Care Model to improve HRQOL and selfmanagement for cancer survivors with ostomies. The design included pre-intervention, postintervention, and 6-month follow-up survey evaluations. This program was approved by the University of Arizona Human Subjects Protection Program (FWA00004218); written, informed consent was obtained from each subject. Initially, we included only colorectal cancer (CRC) survivors due to the preponderance of our background data in this population. In addition, we sought only patients within six months of their ostomy procedure. To enhance accrual, and recognizing many similar issues affect non-CRC survivors and those farther out from surgery, we included all cancer survivors with ostomies. Participants were recruited from multiple sources, including distribution of brochures, direct surgeon or ostomy nurse referral, radio advertisement, or most commonly, from the Tucson Ostomy Support Group peer group sessions. Due to these varied sources of recruitment, the number of ostomates who were approached or heard of the trial is unknown. 


\section{Chronic Care Ostomy Self-Management Program}

Faculty for the group sessions were experienced ostomy nurses, and the same two ostomy nurses (NT and MC) participated throughout this study. Their training included an understanding of their role with the group, review of the curriculum and post session review to identify problems, barriers, and find solutions. Their focus involved training patients to become problem solvers, rather than simply giving them a health professional's solution. For example, potential problem areas (skin problems, pouch selections) were identified by the nurses, and the group was asked how they would approach solving these problems. For those who had experienced the problem, they shared what actions they took with others in the group, demonstrating problem solving approaches. We had a small network of Peer Ostomates who were trained in the program, with one male and one female most commonly used. Peer Ostomates were assigned to participating ostomates by same gender.

\section{Program Curriculum}

The program curriculum was described elsewhere [8]. Briefly, using the Chronic Care Model [9] as a guide, a five session program was designed (Table 1). Sessions were initially approximately every 3 weeks, but midway through the program, based on participant comments, was changed to Sessions 1 and 2 being on one day, followed by sessions 3, 4 and 5 approximately one month later. Teaching methods used for all sessions include adult teaching principles $[16,17]$. These principles include recognizing that adult learners have a variety of life experiences, and can bring much to the discussion about self-care after gastrointestinal surgery. In addition participants will learn most when the content clearly applies to performing activities relevant to their current condition. This interaction, discussion, and demonstrations by participants was encouraged, and provided rich content for the program. Interaction was expected with hands-on laboratory sessions, and rehearsing embarrassing communication challenges that may occur in social settings, public restaurants, church, etc. Group discussion was used to explore what to say, how to say it, and what to do when communicating with others. Patients were expected to come ready to discuss barriers, coping strategies, adjustment timing, equipment problems, eating problems, and sexuality.

\section{Participant Outcomes}

Basic demographic and clinical information was obtained from the City of Hope Quality of Life Ostomy (COH-QOL-O) survey. While we stressed the importance of the surveys, participants were not withdrawn from the study if they did not complete all surveys. The focus was on feasibility and ensuring participation in sessions. Surveys were given at baseline, after sessions 5 ("post-intervention" measures), and at least 6 months after completing the program ("follow-up" measures).

There were multiple surveys used to evaluate this study. The 13-item PAM uses a unidimensional, probabilistic Guttman-like scale that reflects a developmental model of activation and involves four stages: (1) believing the patient role is important, (2) having the confidence and knowledge necessary to take action, (3) actually taking action to maintain and improve one's health, and (4) staying the course even under stress [18]. Those with higher activation scores report significantly better health, and significantly lower rates of doctor office visits, emergency room visits, and hospital nights. The PAM has been shown to have strong psychometric properties and is predictive of most health behaviors and many health outcomes $[19,20]$. The Self-Efficacy questionnaire was modified from Lorig et al.'s Self-Efficacy to Perform Self- 
management Behaviors Scale. An outcome measure for Chronic Disease Management Interventions, this scale represents 8 domains and strong psychometric properties [21]. The COH-QOL-O questionnaire was designed for all adult Ostomates, and has a 4-dimensional HRQOL (physical, psychological, social, and spiritual well-being) framework on 0 to 10 scales. Reported Cronbach's alphas are .94 total scale and .80-.90 subscales [1,22]. The HADS is a selfassessment instrument for detecting anxiety and depression in medical outpatients, which has been demonstrated as sensitive in community and inpatient cancer studies, with reported Cronbach's alpha $=.84-.89$ [23]. The m-GHAA Satisfaction with Ostomy Care Survey is one page and measures overall satisfaction with Ostomy-related care. Developed from the GHAA/Davies \& Ware 1991 GHAA's Consumer Satisfaction Survey, 2nd ed. [24], and modified by our team in Ostomy care areas, it has 7 satisfaction with care domains (Overall, Access, Finances, Technical Quality, Communication, Interpersonal Care, and Outcomes).

\section{Program Evaluations}

After each session, participants completed a session evaluation focused on program content, teaching methods, and personnel. There were multiple scaled and open-ended questions. Scaled item average scores were calculated for questions about: 1) the Ostomy Nurse Educators, 2) the Peer Ostomate Participation, 3) the Sessions, and 4) the Overall Program. Scoring was from $1-5$, with 5 being the best score.

\section{Statistical Analysis}

Scales for all instruments were derived as the arithmetic mean of non-missing items in the scale, according to scoring instructions provided by respective creators. We report Cronbach's alpha for the PAM, Self-Efficacy for Ostomy Management, and the m-GHAA Satisfaction with Ostomy Care, as they were either primary outcomes validated in samples dissimilar to ours or they were modified to apply to ostomy care. We evaluated change in scale scores from pre-intervention to post-intervention and from pre-intervention to follow-up using paired t-tests. We evaluated the association between time since surgery and pre-intervention measures, change scores at post-intervention, and change scores at follow-up for total HRQOL, Patient Activation, and Self-Efficacy for Ostomy Management using Pearson's correlations. Attendance for each session was calculated as the number attending divided by the total participants who had not dropped out before that session. Participant characteristics were compared by attendance status, drop-out status, and survey completion status using two sample ttests for age, Fisher's exact test for sex and cancer type, and Mann-Whitney U test for time since surgery, due to a skewed distribution.

\section{Qualitative Analysis}

Open-ended survey responses were entered into an Excel $^{\complement}$ spreadsheet to facilitate our analysis. The qualitative data were coded using a content analysis approach [25]. All responses were double coded by pairs of researchers, and the entire team met to ensure congruency of coding and resolve any discrepancies. Two members of the study team (MG and RK) reviewed the codes for consistency. Codes were then further collapsed based on the theme that was being expressed. The questions were then collapsed based on the topic being asked so that the final data displayed not only coded responses, but we were also able to depict the responses in a descriptive numeric fashion. 


\section{RESULTS}

Participants

Most participants were recruited from ongoing Tucson-based ostomy groups. Of those eligible for the study, an estimated $20 \%$ opted to take part in program. Thirty-eight subjects enrolled in the study, with 9 drop-outs ( 1 before Session 1, 3 before Session 2, and 5 before Session 4). Reasons for drop-out included death (2), illness (2), early ostomy reversal (1), travel distance (1), and no longer wanting to participate (3). Among those who had not dropped out before the respective session, attendance was relatively high (Session $1=100 \%$, Session $2=$ $97.1 \%$, Session 3 was for caregivers only, Session $4=93.1 \%$, and Session 5 which included caregivers also $=96.6 \%$ ). Almost $70 \%$ of participants were accrued after amendments to include all ostomy survivors with ostomies. While the booster/make-up session 5 was not mandatory, most participants attended. Several participants (4 pre-session, 6 post-session, and 6 follow-up) did not fill out complete surveys due to address change or refusal, yielding outcome measures for 25 pre-session, 23 post-session, and 23 follow-up, of which 21 completed all three surveys. There was no significant difference based on drop-out, attendance, or survey completion status for age, sex, cancer type, or time since surgery.

Participants were predominantly male and rectal cancer survivors (Table 2). Participants rarely contacted peers outside of sessions, although this was available to them. Time between ostomy surgery and baseline survey averaged 201 days (Table 2). There were 17 participants who were confirmed to be less than four months since ostomy, and 14 greater than four months since ostomy. Twenty-two caregivers attended Session 3.

\section{Participant Outcomes}

Reliability was high for instruments that we modified or had been validated in populations different from the present sample: Self-Efficacy for Ostomy Management presession alpha 0.96, post-intervention alpha 0.90, follow-up 0.86; Satisfaction with Ostomy Care pre-session alpha 0.97, post-intervention alpha 0.96, follow-up 0.97; Patient Activation Measure pre-session alpha 0.70 , post-intervention alpha 0.87 , follow-up 0.94 .

Outcome measures generally improved throughout the program, and appeared to be sustained (Table 3). Patient Activation was significantly improved post-intervention $(\mathrm{p}<0.0001)$ and sustained on follow-up $(\mathrm{p}=0.001)$. Patient Activation improved an average of 14.2 points (on a $0-100$ scale) at post-intervention and 11.3 points at follow-up. This represents substantial improvement, as even a 3 point gain is linked with improved health behaviors [26]. Self-Efficacy for Ostomy Management was not significantly improved post-intervention $(p=.07)$ but was significantly improved at follow-up by an average of 1.3 points out of $10(\mathrm{p}=.008)$. Total HRQOL, Physical Wellbeing, and Social Wellbeing from the COH- QOL-O were significantly improved at post-intervention and follow-up. Based on HADS, anxiety decreased with time and was significantly reduced at the time of the follow-up measure $(\mathrm{p}=0.02)$, and a trend was evident towards improvement for depression $(\mathrm{p}=0.09)$. Satisfaction with Ostomy Care was unchanged at post-intervention but significantly improved at follow-up $(\mathrm{p}=.03)$.

There were 14 subjects with duration since surgery $\leq 6$ months, 9 subjects with duration since surgery $>6$ months, and 2 subjects missing this information. There was no significant correlation between duration since surgery and pre-session measures of total HRQOL $(r=-.02$, 
$\mathrm{p}=0.92)$, Patient Activation $(\mathrm{r}=-.08, \mathrm{p}=0.71)$, or Self-Efficacy for Ostomy Management $(\mathrm{r}=\mathrm{-}$ $.08, \mathrm{p}=0.71)$. Likewise, we observed no significant correlation between duration since surgery and change scores at post-intervention $(\mathrm{r}=-.27, \mathrm{p}=0.21 ; \mathrm{r}=-.25, \mathrm{p}=0.28 ; \mathrm{r}=-.20, \mathrm{p}=0.38$; respectively) and follow-up $(r=-.24, p=0.26 ; r=-.37, p=0.10 ; r=-.22, p=0.35$; respectively) for the same three measures, suggesting that the observed improvements were not confined to or explained by subjects with recent surgeries.

\section{Program Evaluations}

Participants gave high-scaled evaluations across sessions 1, 2, 4, and 5 (Session 3 for caregivers). Mean scores across sessions for Ostomy nurse educators were 4.4 to 4.8 , for peer ostomates were 3.8 to 4.3 , for Curriculum were 4.2 to 4.7 , and for overall program evaluation were 4.4 to 4.8. Session evaluations from caregivers echoed those from participants, although there was input that caregiver peers would have been preferred. Text feedback from participants was divided into separate topics addressing the program content, teaching methods, facilities or setting, and general impressions (Table 4). Several additional questions received the most frequent responses. Sixty-five percent of the participants felt they received enough training from these sessions, and 58\% felt comfortable with each session. Only $47 \%$ felt materials were adequate and the most frequent recommendations were having more visual aids, larger groups, and fewer surveys.

\section{DISCUSSION}

Ostomy Self-Management Training program (OSMT) was developed in an effort to improve HRQOL through a systematic self-management program based on the needs of ostomates [8]. While it seems intuitive that there should be a standardized educational curriculum for new ostomy survivors, there is none currently. This may be due to several reasons, including time constraints of Wound Ostomy Continence (WOC) Nurses, absence of reimbursement for such activities, lack of a research team to design such an intervention based on a program of research. Current peri-operative and long-term ostomy care suffers from shorter hospitalizations and lack of formal follow-up or mechanisms to see WOC Nurses outside of the hospital. The goal of OSMT is to reduce this care deficit and assist the adaptation and long-term issues for cancer survivors with the chronic condition of living with an ostomy.

A major goal of the study was to enhance ostomates' control of their own care. This may be in the postoperative setting when there is minimal understanding of the processes of self-care, or later in life when new medical problems or an altered body habitus make continuous learning and practice of ostomy self-care an essential component of care. While the study was designed to test feasibility, continued and sustained improvement in patient activation and self-efficacy were shown. Surveys maintained reliability, enhancing importance of these results. Increases in patient activation scores indicated that participants gained knowledge, skill, and confidence in managing their health. This increased activation is likely necessary for improving well-being and quality of life. When people feel more able to control important aspects of their health, they are more likely to experience positive improvements in social and physical well-being, which the program was designed to address. In fact, we did observe an improvement in physical and social well-being.

The benefit of a standardized program for cancer survivors with ostomies can be derived from evidence that they can benefit from ongoing support, even if they are long-term survivors 
$[6,11]$. Survivors may have issues related to their continuing cancer treatments, such as wound issues or neuropathy [27]. There may be gaps of knowledge that may arise from lack of training or forgetfulness of specific recommendations. As long-term survivors age, they may have problems related to vision, arthritis, or changes in body habitus [28]. Social factors may change, such as the death of a spouse, a child moving away, or retirement [29]. In addition, products and equipment continue to change and improve [30]. Therefore, a program such as OSMT may benefit not only survivors who are in the acute phase of transitioning from active treatment to survivorship, but also to those throughout their survivorship life.

There were challenges in implementing the OSMT program. Most importantly, traveling to a central site was difficult for many survivors. This was often due to distance to travel, but there were multiple individual reasons why it was a challenge. This often led to small or dwindling group size over time, which some participants felt was a detriment to the program. Another negative response reported was the concern several participants had with the burden of completing the battery of surveys. While these were deemed necessary to evaluate the program, these survey instruments would not be required when translating the program in the community.

In response to participant input, we opted to condense sessions and their implications on the curriculum, including response to participant suggestions. This allowed less travel and less delay between sessions which alleviated other difficulties in scheduling sessions on multiple different dates. While there might have been a cost in "practice time" we felt there continued to be ample time between the first and second sessions, where much of the "hands-on" training was done, and sessions four and five. This change did facilitate participation.

Research has shown that cancer survivors who have better physical function and social support had higher levels of self-care self-efficacy [31]. As these measures tend to be worse for both male and female ostomates [4], the improvements we observed indicate that well-designed support programs can make a dramatic and sustainable difference for these patients. We did not see a significant difference in scores for those who had their stomas based on greater or less than six months, and the curriculum did have value for both groups of cancer survivors. This may be due to new products, change in body habitus, new medical problems, or forgetting lessons learned previously.

Related to feelings of depression and anxiety, our study showed trends towards improvements, but did not display large differences. This may be due to several reasons. First, most participants had low scores to begin with. Next, the study was not powered to show a difference, and perhaps would have shown greater statistical significance with larger numbers of participants. Finally, without direct comparisons to those not participating, we cannot know that small improvements one time are directly linked to the curriculum.

Importantly, we found that participants generally enjoyed the sessions and derived benefit as seen by their comments and scores from outcome measures. Across all sessions, the program scored very highly for the ostomy nurse educators, the peer ostomates, the educational content, and the overall program, and qualitative data confirmed this. In addition, reasonable specific recommendations were provided by participants. Most importantly, ways to increase participants per session must be considered. Several participants did not complete the curriculum, with 
reasons including death, illness, travel issues, or early ostomy reversal. We do not believe these issues should influence the implementation of the program in other communities.

While there is evidence of benefit of support groups for cancer survivors, there are also noted to be high rates of refusal and approximately 20\% rates of drop-out [32-34], which may lead to a participation bias. There is evidence of peer-group sessions being advantageous for ostomy survivors [35]. In addition, we have shown that groups that had ostomy nurse [35] and Peer Ostomate [36] participation were beneficial. The OSMT program builds on this evidence with a systematic curriculum based on input from many cancer survivors with ostomies. While it has been shown that an educational program has benefit [37], there has not been a similar rigorous curriculum based specifically on ostomy cancer survivor input. Therefore, our curriculum specifically addressed areas of need while allowing for interaction and learning from ostomy nurses, peers, and participants.

Several limitations of this study must be noted. First, it was a feasibility pilot study, and thus our participant numbers were small. A centralized delivery of the curriculum may have led, in part to accrual difficulties. Other mechanisms of delivery, such as telehealth, could have made the program more accessible. Second, patients with fewer resources and greater social disparities are not as likely to access health care or participate in research [38-42]; our results are likely biased due to the difficulties of including diverse participants. Third, we had multiple surveys that represented response burdens to some participants who continued in the program (but did not complete the forms). Our priority was to have ostomy survivors participate, add to the group structure of the sessions, and then to obtain survey feedback. Fifth, as patient HRQOL likely improves with time after surgery [43] (although HRQOL may incrementally decrease as one ages and is further from their operation), it is not possible to claim definitively that the higher scores in multiple surveys are due to the OSMT program. It is likely that multiple participants did have improvements due to the program as many of them had their ostomy placed in the more remote past. Therefore, they likely had time to adjust but either had ongoing problems or new issues arose. To verify the benefits of the program, the intervention must be compared to ostomates undergoing usual care in their community. Finally, this study had a limited focus on caregivers. While caregivers were included primarily to augment participant education, we did elucidate some qualitative input from them. Future studies should focus on further understanding caregivers' role and resources in the program to assist their role.

In conclusion, the OSMT program is a novel chronic care program focused on cancer survivors with ostomies who have completed their cancer treatments. In this feasibility study, we demonstrated this program impacted cancer survivors with ostomies patient activation and selfefficacy to manage their ostomies, and their HRQOL. This evidence-based program met participant and caregiver ongoing needs, and set the stage for a larger study utilizing innovative implementation methods, responsive to participant wishes, to help cancer survivors with ostomies.

\section{ACKNOWLEDGEMENTS}

The authors do not have any conflicts of interest.

\section{FUNDING}




\section{Chronic Care Ostomy Self-Management Program}

This work was supported by grants from the National Cancer Institute at the National Institutes of Health (grant number R21 CA133337, and Arizona Cancer Center Support Grant number CA023074). The funders had no role in the design and conduct of the study, collection, management, analysis and interpretation of the data, preparation, review or approval of the manuscript. 


\section{REFERENCES}

1. Grant M, Ferrell B, Dean G, Uman G, Chu D, Krouse R. Revision and psychometric testing of the City of Hope Quality of Life-Ostomy Questionnaire. Qual Life Res 2004; 13: 14451457.

2. Krouse R, Grant M, Ferrell B, Dean G, Nelson R, Chu D. Quality of Life Outcomes in 599 Cancer and Non-Cancer Patients with Colostomies. J Surg Res 2007; 138: 79-87.

3. Krouse RS, Grant M, Wendel CS, et al. A mixed-methods evaluation of health-related quality of life for male veterans with and without intestinal stomas. Dis Colon Rectum 2007; 50: 2054-2066.

4. Krouse RS, Herrinton LJ, Grant M, et al. Health-related quality of life among long-term rectal cancer survivors with an ostomy: manifestations by sex. J Clin Oncol 2009; 27: 46644670.

5. Tallman NJ, Cobb MD, Grant M, et al. Colostomy irrigation: issues most important to Wound, Ostomy and Continence nurses. J Wound Ostomy Continence Nurs In press.

6. Sun V, Grant M, McMullen CK, et al. Surviving colorectal cancer: Long-term, persistent ostomy-specific concerns and adaptations. J Wound Ostomy Continence Nurs 2013; 40: 6172.

7. Wasserman M, Baxter NN, Rosen B, Burnstein M, Halverson AL. Systematic review of internet patient information on colorectal cancer surgery. Dis Colon Rectum 2014; 57: 64-69.

8. Grant M, McCorkle R, Hornbrook MC, Wendel CS, Krouse R. Development of a chronic care ostomy self management program. J Cancer Educ 2013; 28: 70-78.

9. Wagner EH, Austin BT, Davis C, Hindmarsh M, Schaefer J, Bonomi A. Improving chronic illness care: translating evidence into action. Health Aff 2001; 20: 64-78.

10. Krouse RS, Grant M, Rawl SM, et al. Coping and acceptance: the greatest challenge for veterans with intestinal stomas. J Psychosom Res 2009; 66: 227-233.

11. McMullen CK, Hornbrook MC, Grant M, et al. The greatest challenges reported by longterm colorectal cancer survivors with stomas. J Support Oncol 2008; 6: 175-182.

12. Altschuler A, Ramirez M, Grant M, et al. The influence of husbands' or male partners' support on women's psychosocial adjustment to having an ostomy resulting from colorectal cancer. J Wound Ostomy Continence Nurs 2009; 36: 299-305.

13. McMullen CK, Hornbrook MC, Herrinton LJ, et al. Improving Survivorship Care for LongTerm Colorectal Cancer Survivors: Key Findings of a 5-Year Study. Clin Med Res 2010; 8: 32-33.

14. Grant M, McMullen CK, Altschuler A, et al. Irrigation practices in long-term survivors of colorectal cancer with colostomies. Clin J Oncol Nurs 2012; 16: 514-519.

15. Grant M, Krouse R, McMullen C, et al. Dietary adjustments reported by colorectal cancer (CRC) survivors with permanent ostomies. J Cancer Educ Supplement 2007; 22: 33.

16. Knowles MS. The adult learner: a neglected species. $4^{\text {th }}$ ed. Houston, TX: Gulf Publishing; 1990.

17. Pike RW. Creative training techniques handbook: tips, tactics, and how-to's for delivering effective training. $2^{\text {nd }}$ ed. Minneapolis, MN: Lakewood Books; 1994.

18. Hibbard J, Mahoney E, Stockard J, Tusler M. Development and testing of a short form of the PAM. Health Serv Res 2005; 40: 1918-1930.

19. Skolasky RL, Green AF, Scharfstein D, Boult C, Reider L, Wegener ST. Psychometric properties of the patient activation measure among multimorbid older adults. Health Serv Res 2011; 46: 457-478. 
20. Hibbard JH, Greene J. What the evidence shows about patient activation: better health outcomes and care experiences; fewer data on costs. Health Aff (Millwood) 2013; 32: 207214.

21. Lorig K, Stewart A, Ritter P, González V, Laurent D, \& Lynch J, Outcome Measures for Health Education and other Health Care Interventions. Thousand Oaks CA: Sage Publications, 1996.

22. Mohler MJ, Coons SJ, Hornbrook MC, et al. The health-related quality of life in long-term colorectal cancer survivors study: objectives, methods and patient sample. Curr Med Res Opin 2008; 24: 2059-2070.

23. Cameron IM, Crawford JR, Lawton K, Reid IC. Psychometric comparison of PHQ-9 and HADS for measuring depression severity in primary care. Br J Gen Pract 2008; 58: 32-6.

24. Davies AR, Ware JE. GHAA's Consumer Satisfaction Survey and user's manual. $2^{\text {nd }}$ ed. Washington, DC: Group Health Association of America; 1991.

25. Hsieh, HF, Shannon SE. Three approaches to qualitative content analysis. Qual Health Res 2005; 15: 1277-1288.

26. Fowles JB, Terry P, Xi M, Hibbard J, Bloom CT, Harvey L. Measuring self-management of patients' and employees' health: further validation of the Patient Activation Measure (PAM) based on its relation to employee characteristics. Patient Educ Couns 2009; 77: 116-122.

27. Salvaladena G. Incidence of complications of the stomal and peristomal skin among individuals with colostomy, ileostomy, and urostomy. J. Wound Ostomy Continence Nurs 2008: 35; 596-607.

28. Skeps RP, McMullen CK, Wendel CS, Bulkley J, Grant M, Mohler J, Hornbrook MC, Krouse RS, Herrinton LJ. Changes in body mass index and stoma related problems in the elderly. J Geriatr Oncol 2013; 4: 84-89.

29. Leyk M, Ksiaz'ek J, Habel A, Dobosz M, Kruk A, Terech S. The influence of social support from the family on health related-quality of life in persons with a colostomy. $J$ Wound Ostomy continence Nurs 2014; 41: 581-587.

30. Prinz A, Colwell JC, Cross HH, Mantel J, Perkins J, Walker CA. Discharge planning for a patient with a new ostomy. J Wound Ostomy Continence Nurs 2015; 42: 79-82.

31. Qian H, Yuan Changrong. Factors associated with self-care self-efficacy among gastric and colorectal cancer patients. Cancer Nurs 2012; 35: E22-E31.

32. Slevin ML, Nichols SE, Downer SM, et al. Emotional support for cancer patients: what do patients really want? Br J Cancer 1996; 74: 1275-1279.

33. Goodwin PJ, Leszcz M, Ennis M, et al. The effect of group psychosocial support on survival in metastatic breast cancer. N Engl J Med 2001; 345: 1719-1726.

34. Classen C, Butler LD, Koopman C, et al. Supportive-expressive group therapy and distress in patients with metastatic breast cancer: a randomized clinical intervention trial. Arch Gen Psychiatry 2001; 58: 494-501.

35. Mowdy S. The role of the WOC nurse in an ostomy support group. $J$ Wound Ostomy Continence Nurs 1998; 25: 51-54.

36. Trainor MA. Stomas. Self-help groups Part 2. Clin Gastroenterol 1982; 11: 415-419.

37. Altuntas YE, Kement M, Gezen C, et al. The role of group education on quality of life in patients with a stoma. Eur J Cancer Care 2012; 21: 776-781.

38. Wielen LM, Gilchrist EC, Nowels MA, Petterson SM, Rust G, Miller BF. Not Near Enough: Racial and Ethnic Disparities in Access to Nearby Behavioral Health Care and Primary Care. J Health Care Poor Underserved. 2015; 26: 1032-1047. 


\section{Chronic Care Ostomy Self-Management Program}

39. Mandimika CL, Murk W, Mcpencow AM, et al. Racial Disparities in Knowledge of Pelvic Floor Disorders Among Community-Dwelling Women. Female Pelvic Med Reconstr Surg. 2015; 21: 287-292.

40. Smith AK, Shara NM, Zeymo A, et al. Travel patterns of cancer surgery patients in a regionalized system. J Surg Res 2015 Apr 9. Pii: S0022-4804(15)00413-8. Doi: 10.1016/j.jss.2015.04.016. [Epub ahead of print].

41. Leiter A, Deifenbach MA, Doucette J, Oh WK, Galsky MD. Clinical trial awareness: Changes over time and sociodemographic disparities. Clin Trials 2015; 12: 215-223.

42. Frew PM, Omer SB, Parker K, et al. Delivering a "dose of hope": a faith-based program to increase older African Americans' participation in clinical trials. JMIR Res Protoc 2015; 4: e64.

43. Schmidt CE, Bestmann B, Kuchler T, Longo WE, Rohde V, Kremer B. Gender differences in quality of life of patients with rectal cancer. A five-year prospective study. World J Surg 2005; 29: 1630-1641. 


\section{Table 1. Training Session Description}

\begin{tabular}{|c|c|}
\hline Session & Content \\
\hline 1 & $\begin{array}{l}\text { Self-management and immediate ostomy concerns - Teaching methods are interactive } \\
\text { with hands on practice with equipment, pouches, and belts. Issues discussed included: } \\
\text { Disease states } \\
\text { Daily care } \\
\text { Nutritional needs } \\
\text { Skin care } \\
\text { Clothing changes }\end{array}$ \\
\hline 2 & $\begin{array}{l}\text { Social well-being and body image - Deals with the problems of: } \\
\text { Social/interpersonal relationships } \\
\text { Public appearances } \\
\text { Being prepared for emergencies } \\
\text { Intimacy and sexuality } \\
\text { Communication skills }\end{array}$ \\
\hline 3 & $\begin{array}{l}\text { Spouse/Significant Other/Designee Session - Cover same topics as Ostomate sessions that } \\
\text { are specifically tailored to support and adjustment of caregiver to achieve a comfort level } \\
\text { with ostomies. Not all participants had a designee. }\end{array}$ \\
\hline 4 & $\begin{array}{l}\text { Healthy lifestyle - Discussion includes: } \\
\text { Nutritional management } \\
\text { Physical activity recommendation and overcoming barriers } \\
\text { Psychological health } \\
\text { Improving attitudes } \\
\text { Travel }\end{array}$ \\
\hline 5 & $\begin{array}{l}\text { Booster Session (Ostomate and Session } 3 \text { participant) - Review of daily care, } \\
\text { psychological impact, and nutrition/exercise problems. The group demands and needs drive } \\
\text { the content for this session. }\end{array}$ \\
\hline
\end{tabular}


Chronic Care Ostomy Self-Management Program

Table 2. Demographic Characteristics of Participants

\begin{tabular}{|l|c|}
\hline Characteristic & $\begin{array}{c}\text { Summary } \\
\mathbf{N}=\mathbf{3 8}\end{array}$ \\
\hline Age, years [mean (SD)] & $21.3(7.4)[$ range 60-82] \\
\hline Male & 32 \\
\hline Race & 1 \\
White, non-Hispanic & 1 \\
White, Hispanic & \\
Black & $23(60.5)$ \\
\hline Cancer type, n (\%) & $11(28.9)$ \\
CRC & $1(2.6)$ \\
Bladder/Prostate & $3(7.8)$ \\
Ovarian & \\
Unknown & $23(52.7)$ \\
\hline Stoma type, n (\%) & $11(28.9)$ \\
Colostomy/ileostomy & $4(10.5)$ \\
\hline Urostomy & $201(305)[$ range 22 - 1,626] \\
\hline Unknown &
\end{tabular}


Chronic Care Ostomy Self-Management Program

Table 3. Intervention Outcomes

\begin{tabular}{|c|c|c|c|c|c|}
\hline Measure & $\begin{array}{c}\text { Pre-Sessions } \\
\quad(n=25)\end{array}$ & $\begin{array}{l}\text { Post-Sessions } \\
\qquad(\mathrm{n}=\mathbf{2 3})\end{array}$ & $\begin{array}{c}\text { T-value } \\
\left.\text { (P value }^{1}\right)\end{array}$ & $\begin{array}{l}\text { Follow-up } \\
(\mathbf{n}=\mathbf{2 3})\end{array}$ & $\begin{array}{c}\text { T-value } \\
\left(P \text { value }^{2}\right)\end{array}$ \\
\hline $\begin{array}{l}\text { Patient Activation } \\
\text { Measure }\end{array}$ & $63.3 \pm 13.3$ & $78.2 \pm 13.9$ & $\begin{array}{l}-5.526 \\
(<.0001)\end{array}$ & $74.5 \pm 17.4$ & $\begin{array}{r}-3.697 \\
(.001)\end{array}$ \\
\hline $\begin{array}{l}\text { Self-Efficacy for Ostomy } \\
\text { Management }\end{array}$ & $6.8 \pm 2.4$ & $7.8 \pm 1.9$ & $\begin{array}{r}-1.919 \\
(.07)\end{array}$ & $8.2 \pm 1.6$ & $\begin{array}{r}-2.912 \\
(.008)\end{array}$ \\
\hline Total Ostomy QOL & $6.3 \pm 1.8$ & $7.0 \pm 1.8$ & $\begin{array}{c}-2.484 \\
(.02)\end{array}$ & $7.1 \pm 1.7$ & $\begin{array}{c}-2.397 \\
(.03)\end{array}$ \\
\hline Physical Wellbeing & $6.6 \pm 1.8$ & $7.4 \pm 1.8$ & $\begin{array}{c}-2.497 \\
(.02)\end{array}$ & $7.5 \pm 1.6$ & $\begin{array}{c}-2.683 \\
(.01)\end{array}$ \\
\hline $\begin{array}{l}\text { Psychological } \\
\text { Wellbeing }\end{array}$ & $6.4 \pm 1.8$ & $6.8 \pm 2.0$ & $\begin{array}{c}-1.332 \\
(.20)\end{array}$ & $7.0 \pm 1.9$ & $\begin{array}{c}-1.528 \\
(.14)\end{array}$ \\
\hline Social Wellbeing & $5.9 \pm 2.0$ & $7.1 \pm 1.9$ & $\begin{array}{l}-3.539 \\
(.002)\end{array}$ & $7.0 \pm 1.9$ & $\begin{array}{l}-3.116 \\
(.005)\end{array}$ \\
\hline Spiritual Wellbeing & $6.4 \pm 2.4$ & $6.3 \pm 2.2$ & $\begin{array}{c}-0.061 \\
(.95)\end{array}$ & $6.8 \pm 2.3$ & $\begin{array}{c}-0.473 \\
(.64)\end{array}$ \\
\hline HADS $^{3}$ Anxiety & $6.1 \pm 4.4$ & $5.6 \pm 4.4$ & $\begin{array}{c}0.814 \\
(.42)\end{array}$ & $4.6 \pm 3.5$ & $\begin{array}{l}2.556 \\
(.02)\end{array}$ \\
\hline $\mathrm{HADS}^{3}$ Depression & $5.1 \pm 3.8$ & $4.5 \pm 3.9$ & $\begin{array}{r}0.982 \\
(.34)\end{array}$ & $4.0 \pm 3.6$ & $\begin{array}{l}1.776 \\
(.09)\end{array}$ \\
\hline $\begin{array}{l}\text { Satisfaction with Ostomy } \\
\text { Care }\end{array}$ & $3.8 \pm .87$ & $3.8 \pm 1.2$ & $\begin{array}{c}0.000 \\
(.99)\end{array}$ & $4.4 \pm .74$ & $\begin{array}{c}-2.351 \\
(.03)\end{array}$ \\
\hline
\end{tabular}

${ }^{1}$ Pre-sessions versus post-sessions, paired t-test

${ }^{2}$ Pre-sessions versus follow-up, paired t-test

${ }^{3}$ Hospital Anxiety and Depression Scale scores range $0-21$, where 7 or less is considered normal 


\section{Chronic Care Ostomy Self-Management Program}

\section{Table 4. Session Feedback from Participants}

\begin{tabular}{|c|l|}
\hline Session subjects & Feedback \\
$\begin{array}{c}\text { Program Content } \\
\text { Why valuable? }\end{array}$ & Applicable, professional, good information and content, great staff \\
What was missing? & $\begin{array}{l}\text { Company contacts, need more actual practice, more physiology, more } \\
\text { advanced content }\end{array}$ \\
\hline $\begin{array}{c}\text { Teaching Methods } \\
\text { What was valuable? }\end{array}$ & $\begin{array}{l}\text { Discussion, DVD and Visuals, small groups, nurse-educators, peer } \\
\text { discussion }\end{array}$ \\
What was missing? & More hands on, more discussion, more participants \\
\hline $\begin{array}{c}\text { Facilities/Setting } \\
\text { What recommended? }\end{array}$ & $\begin{array}{l}\text { Closer to surgery time, less time between sessions, snacks, support for } \\
\text { travel }\end{array}$ \\
\hline $\begin{array}{l}\text { Impressions of the } \\
\text { Group? }\end{array}$ & $\begin{array}{l}\text { Valuable peer ostomates, same kind of ostomy, camaraderie within the } \\
\text { group }\end{array}$ \\
\hline
\end{tabular}

